\title{
Editorial: What We Can Afford and What Counts
}

\author{
Donald A. Hantula ${ }^{1}$
}

Published online: 6 July 2017

(C) Association for Behavior Analysis International 2017

As the flagship journal of the world's largest association devoted to behavior analysis, The Behavior Analyst (TBA) exists to present leading edge theory and methodology of relevance to anyone who makes a home on the broad landscape of behavior analysis and behavioral science. As befits that mission, the papers in this issue stretch theoretical and conceptual boundaries and point to new collaborations and future directions in the field. We begin with a special section examining the concept of reinforcement, the nature of Applied Behavior Analysis (ABA) research, and strategies for disciplinary survival. The papers and commentaries addressing them, ask us to contemplate difficult and perhaps uncomfortable questions facing behavior analysis and behavioral science. We then move to our regularly scheduled programming with papers exploring neuroscience, multiple exemplar training, incarceration, and psychotherapy, along with a methodological paper and a memorial to a pioneering researcher.

\section{Of Jets and Sharks}

There is a scene in the classic film Annie Hall in which a couple on a bicoastal flight are discussing their relationship. One observes that a relationship is like a shark - it must keep moving forward or else it dies, and then concludes that what they have on their hands is essentially, a dead shark. A scientific discipline is much like that - it too must keep moving forward, otherwise it dies. The special section The Future of Behavioral Science and Behavior Analysis is a collective attempt to keep our shark moving, alive, and not turned into hákarl.

Can We Afford Reinforcement? A target article by Killeen and Jacobs challenges what we think we may know about reinforcement, and makes a cogent argument to move beyond the well known A-B-C triplet to the quadruple $\mathrm{O}: \mathrm{S}_{\mathrm{D}}-\mathrm{R}_{\mathrm{I}}-\mathrm{R}_{\mathrm{C}}$. Their

Donald A. Hantula

hantula@temple.edu

1 Temple University, Weiss Hall, 1701 N. 13 St, Philadelphia, PA 19122, USA 
analysis then reconsiders reinforcement not as a thing or an activity, but as a relation. Relying on the Gibsonian concept of affordances, they propose to (re)introduce the organism into the fundamental framework of behavior analysis. This idea may not be as radical as it may seem. Hineline (1992) observed that, "Behavior is the interaction between organism and environment. And, the organism is a locus where behavior and environment interact (p. 1284)." With the growing interest in how neuroscience, behavioral genetics, and epigenetics relate to behavior, it is time to revisit this issue with respect to theory and empirical research. Many eminent behavioral scientists wrote excellent and provocative commentaries, which Tom Critchfield and Johnathan Miller handled with great skill; their introduction to this collection of papers is a great primer on the critical issues raised. Some commentators agree with Killeen and Jacobs' position, some disagree, and others aver that other advances in behavioral theory already address the concerns raised in the paper. The commentaries and the author reply should be read as a whole, as they represent some of the best theorizing in our field.

The Magic Number 7, plus 50 The second paper by Critchfield and Reed moves to the applied side of the field, critically examining the nature of ABA research and what the authors characterize as its doctrinaire adherence to 7 dimensions proposed decades ago by Baer, Wolf, \& Risley (1968; hereafter referred to as BWR). Because Tom Critchfield is an Associate Editor of this journal the review process was handled independently by Mark Galizio. Professor Galizio also decided that commentaries should accompany this article. The resulting examination of ABA's fundamental features is long overdue. BWR's iconic article is clearly a product of its time, but times have changed. Drastically. Although the BWR paper was meant to be heuristic, not definitive, its 7 dimensions have regrettably become enshrined as "the definition" of ABA. Problems begin with the title of the BWR paper itself: Some [not all] Current [1968!!] Dimensions of Applied Behavior Analysis (but the title is also a testament to the authors' wisdom and humility). Any reasonable person may question the legitimacy of a science, or its application, that adheres to methodological monism and a fifty year old foundation. In the case of ABA, BWR's preferred data collection techniques, research designs, reliability criteria and measurement strategies were largely periodpiece products, borne of technological limitations and a quest for standards for an emerging field. Somehow, however, "some" became "all" and "current" became "timeless." BWR is a point of departure, not a destination. Critchfield and Reed's paper, and the accompanying commentaries contributed by students of BWR and other applied researchers, raise two important questions: What then is ABA? And who will lead the next revolution to redefine the field for this century? A Feyerabendian "anything goes" nihilism is probably not a good answer, but then neither is a dismissal of their concerns or another overly strict set of dimensions. Perhaps we can approach an answer to the first question. How about going back to basics: $\mathrm{ABA}=$ an application of operant behavioral science? As for the second question - any volunteers?

A Field Divided Cannot Stand The section finishes with Jack Marr's 2016 ABAI Presidential address in which he revisits the idea that basic and applied behavior analysis are evolving into different species (Rider, 1991). Twenty-some years ago this may have appeared inevitable, but somehow such speciation has not yet happened. Or 
maybe it is occurring, but very slowly. In either case, a parting is not necessarily inevitable, and it is in the field's best interests to stop any separation. Both the experimental and applied sides need one another to survive. If EAB (Experimental Analysis of Behavior) cannot continually provide evidence of social relevance, its prospects for public support and funding are dim, despite scientific advances. If ABA abandons its science base, its authority and prospects for public support will vanish. Without a clear and advancing scientific foundation, ABA becomes no more than a cookbook and bag of tricks, with no need for journals, conferences, or certifications. And in that case it certainly cannot command respect. On the other hand, this alleged speciation may be illusory, and what Marr (and others) observe is a slow sinking of relevance and public support for behavior analysis as a whole (either EAB or ABA), and the infighting we see is occasioned by a dearth of resources. We know quite a bit about the effects of deprivation; it is not solely a motivating operation for food or other reinforcement. Deprivation is also a motivating operation for aggression, competition (Belozertseva, Sukhotina, Vossen, \& Bespalov, 2004) and also cannibalism (Scharf, 2016). It would be best if we did not eat each other.

Behavior More than Counts Marr also identifies a lack of quantitative knowledge as a systemic problem bedeviling behavior analysis, especially the applied side. As Marr notes, people come to behavior analysis largely from programs in education and psychology, two undergraduate majors not known for their quantitative sophistication. Most of these programs do not even require calculus. Yet mathematics is the language of science. Science advances through quantitative theory and application which goes far beyond "fidget with digits" arithmetic operations to logic, reasoning, precision, and prediction. Applied behavior analysts sometime accuse EAB of being "esoteric," but perhaps it would seem less so if there was a higher level of quantitative sophistication in the applied world.

There are many other benefits to more quantitatively oriented application. Take, for example, the challenge of predicting reinforcers. Killeen and Jacobs present one perspective in this issue (and provide a tutorial in linear algebra to help understand their argument). Contrary to claims in poorly written texts, reinforcers can be predicted a priori when theory is paired with quantitative sophistication, as demonstrated by work in behavior regulation (Hagge \& Van Houten, 2016; Jacobs, Morford, King, \& Hayes, 2017; Konarski, Crowell, \& Duggan, 1985; Konarski, Crowell, Johnson, \& Whitman, 1982; Konarski, Johnson, Crowell, \& Whitman, 1980, 1981; Timberlake \& Allison, 1974; Timberlake \& Farmer-Dougan, 1991) and behavioral economics (Borrero, Francisco, Haberlin, Ross, \& Sran, 2007; Donaldson, DeLeon, Fisher, \& Kahng, 2014; Foxall, 2015, 2016; Hursh, 1980; Hursh \& Roma, 2016; Oliveira-Castro, Cavalcanti, \& Foxall, 2016; Peery \& Fisher, 2001; Reed, Kaplan, Becirevic, Roma, \& Hursh, 2016; Roane, Falcomata, \& Fisher, 2007; Tustin, 1994).

Behavioral momentum theory (Nevin, Mandell, \& Atak, 1983) has provided direction for innovative application (Cowan, Abel, \& Candel, 2017; Greer, Fisher, Romani, \& Saini, 2016; Hall, Smith, \& Wynne, 2015; Kelly \& Holloway, 2015; Lambert, Bloom, Samaha, Dayton, \& Kunnavatana, 2016; Nevin, 1996; Nevin et al., 1983; Nevin \& Shahan, 2011; Pritchard, Hoerger, \& Mace, 2014; Roane, Kelley, Trosclair, \& Hauer, 2004), and the important and effective applications of the matching law are ample (Borrero \& Vollmer, 2002; Foxall, 2015; Herrnstein, 1961, 1970; C. McDowell 
\& Keenan, 2001; J. J. McDowell, 1988; J. J. McDowell \& Caron, 2010; Murray \& Kollins, 2000; Rivard, Forget, Kerr, \& Bégin, 2014; St. Peter et al., 2005). The work in stimulus equivalence and relational frame theory which has spawned many applications (Albright, Reeve, Reeve, \& Kisamore, 2015; Albright, Schnell, Reeve, \& Sidener, 2016; Cassidy, Roche, Colbert, Stewart, \& Grey, 2016; Gilroy, Lorah, Dodge, \& Fiorello, 2015; Hausman, Borrero, Fisher, \& Kahng, 2017; Hayes, 2016; Thirus, Starbrink, \& Jansson, 2016; Zinn, Newland, \& Ritchie, 2015) is algebraic in its foundation.

Quantitative literature reviews and meta analyses, even of single-subject designs, are much more authoritative and useful than qualitative or "box score" reviews (Shadish, 2014; Tate et al., 2016), and they also allow for answering larger questions about intervention effectiveness, and equally important, limits. In a world in which the replicability and reproducibility of behavioral and psychological results are in serious question (Open Science, 2015), more rigorous research summaries can only improve the status of behavior analytic research and application; after all, replication is at the core of behavioral research. As a science and its applications advance so will its quantitative sophistication; a field in which "data analysis" consists largely of dropping dots on a graph has little future. Marr's paper reminds us that there is much work to be done. To that end, TBA encourages and publishes quantitative tutorials and tools such as the Appendix in Killeen and Jacobs, and other papers (Bullock, Fisher, \& Hagopian, 2017; Greer et al., 2016; Kaplan et al., 2016).

\section{Going Forward}

The next papers in this issue point us toward new directions in research and application, showcasing the breadth of behavioral research and the depth of its theory and analysis.

Exemplary Bridges Daniele Ortu and Manish Vaidya show how research and theory in behavior analysis and neuroscience are complementary. Reprising Skinner's view of private events, they detail how brain responses and neural activity need be not interpreted as causes of behavior, but rather may be interpreted as behavior. Neuroscientists are recognizing that a complete neuroscientific analysis needs behavior (Krakauer, Ghazanfar, Gomez-Marin, MacIver, \& Poeppel, 2017); similarly, a complete behavioral analysis needs neural activity. The conceptual shift that Ortu and Vaidya propose has great potential for theory, research and application.

Per Holth suggests that multiple exemplar training, which has become one of the bedrock notions in some areas of applied behavior analysis, may have been uncritically accepted as a panacea for promoting generalization. He proposes a mediated generalization model to explain instances in which there are no physical dimensions along which generalized performances can emerge, or if the relation between a stimulus and response is complex. This model will serve as a guide for more advanced research questions and training applications that approach more complex repertoires.

Social Issues, Psychotherapy and Software The following three articles approach applied topics. Alexis Apel and James Diller offer a behavioral perspective on one of the most pressing social problems in the USA: incarceration. They argue that if prison 
is punishment, it is an ineffective punisher. Their paper provides a preliminary behavioral analysis of the problem and suggests that a solution must be a multidisciplinary effort, which may avoid some of the problems that arose in past behavioral applications in corrections (Rutherford, 2006). Their recommendations are very much in line with advances in behavioral systems analysis (Diener, McGee, \& Miguel, 2009; Ludwig \& Houmanfar, 2009; Malott, 2016; McGee \& Diener, 2010; Reimer \& Houmanfar, 2017; Sigurdsson \& McGee, 2015), so perhaps this paper may occasion some synergy.

Oscar Córdoba-Salgado reviews Functional Analytic Psychotherapy, placing it clearly in the larger theoretical framework of the matching law. This paper is an excellent demonstration of how basic research and quantitative reasoning can yield a useful, effective, and scalable solution to applied problems.

Christopher Bullock, Wayne Fisher and Louis Hagopian describe BDataPro, a software application for data collection. Returning to many of the issues raised in the commentaries on Critchfield's and Reed's BWR paper in this issue, the BDataPro paper shows that data collection need not, and should not, be constrained to 50 year old solutions. This is a very useful and user-friendly program and additional validation of its utility may be found in a recent thesis (Gill, 2016). The online version provides instructions and a link for downloading the program, consistent with TBA's initiatives to go beyond the page (Greer et al., 2016; Hantula, 2016; Kaplan et al., 2016; Keenan, 2016). A twenty-first century journal should not be constrained to seventeenth century technology - printed scientific communications (Andrade, 1965).

In Memoriam: Looking Backward to Look Ahead The issue finishes with a fond farewell to one of the most innovative scientists in the field, Gerry Patterson. The journal is grateful to Per Holth for penning a snapshot of Dr. Patterson's life and outlining some of his many contributions to understanding and treating childhood aggression. Patterson sought identify multiple sources of reinforcement for aggression available in the natural environment, and then use this knowledge to develop, test and validate treatments. Readers unfamiliar with this excellent work can start by perusing some of Patterson's more influential books (G. R. Patterson, 1982), book chapters (G. Patterson \& Reid, 1970; G. R. Patterson, 2016; G. R. Patterson, DeBaryshe, \& Ramsey, 1989; G. R. Patterson \& Yoerger, 1997, 2002) and journal articles (G. R. Patterson, 1986, 1993, 2005). Those who do will be treated to a bold vision of how applied behavioral science can deviate from the strict BWR framework and yet, as Jack Marr recommends for all of behavior analysis, remain theoretically rich, quantitatively sophisticated, and engaging to interdisciplinary audiences.

Acknowledgements I thank Erin Rasmussen and Tom Critchfield for their comments on this editorial.

\section{References}

Albright, L., Reeve, K. F., Reeve, S. A., \& Kisamore, A. N. (2015). Teaching statistical variability with equivalence-based instruction. Journal of Applied Behavior Analysis, 48(4), 883-894. doi:10.1002 jjaba.249. 
Albright, L., Schnell, L., Reeve, K. F., \& Sidener, T. M. (2016). Using stimulus equivalence-based instruction to teach graduate students in applied behavior analysis to interpret operant functions of behavior. Journal of Behavioral Education, 25(3), 290-309. doi:10.1007/s10864-016-9249-0.

Andrade, E. d. C. (1965). The birth and early days of the philosophical transactions. Notes and Records of the Royal Society of London, 9-27.

Baer, D. M., Wolf, M. M., \& Risley, T. R. (1968). Some current dimensions of applied behavior analysis. Journal of Applied Behavior Analysis, 1(1), 91-97. doi:10.1901/jaba.1968.1-91.

Belozertseva, I. V., Sukhotina, I. A., Vossen, J. M. H., \& Bespalov, A. Y. (2004). Facilitation of aggressive and sexual behaviors by saccharin deprivation in rats. Physiology \& Behavior, 80(4), 531-539. doi:10.1016/j. physbeh.2003.10.012.

Borrero, J. C., Francisco, M. T., Haberlin, A. T., Ross, N. A., \& Sran, S. K. (2007). A unit price evaluation of severe problem behavior. Journal of Applied Behavior Analysis, 40(3), 463-474. doi:10.1901 /jaba.2007.40-463.

Borrero, J. C., \& Vollmer, T. R. (2002). An application of the matching law to severe problem behavior. Journal of Applied Behavior Analysis, 35(1), 13-27. doi:10.1901/jaba.2002.35-13.

Bullock, C. E., Fisher, W. W., \& Hagopian, L. P. (2017). Description and validation of a computerized behavioral data program: 'bdatapro'. The Behavior Analyst. doi:10.1007/s40614-016-0079-0.

Cassidy, S., Roche, B., Colbert, D., Stewart, I., \& Grey, I. M. (2016). A relational frame skills training intervention to increase general intelligence and scholastic aptitude. Learning and Individual Differences, 47, 222-235. doi:10.1016/j.lindif.2016.03.001.

Cowan, R. J., Abel, L., \& Candel, L. (2017). A meta-analysis of single-subject research on behavioral momentum to enhance success in students with autism. Journal of Autism and Developmental Disorders, 47(5), 1464-1477. doi:10.1007/s10803-017-3076-6.

Diener, L. H., McGee, H. M., \& Miguel, C. F. (2009). An integrated approach for conducting a behavioral systems analysis. Journal of Organizational Behavior Management, 29(2), 108-135. doi:10.1080 /01608060902874534.

Donaldson, J. M., DeLeon, I. G., Fisher, A. B., \& Kahng, S. (2014). Effects of and preference for conditions of token earn versus token loss. Journal of Applied Behavior Analysis, 47(3), 537-548. doi:10.1002/jaba. v47.3. Document Type: journal DOI:10.1002/jaba.135.

Foxall, G. R. (2015). Consumer behavior analysis and the marketing firm: bilateral contingency in the context of environmental concern. Journal of Organizational Behavior Management, 35(1-2), 44-69. doi:10.1080/01608061.2015.1031426.

Foxall, G. R. (2016). Operant behavioral economics. Managerial and Decision Economics, 37(4-5), $215-223$. doi: $10.1002 / \mathrm{mde} .2712$.

Gill, A. (2016). An evaluation of teaching individuals with autism to accept "no.". (Masters thesis), Temple University, Philadelphia, PA. Retrieved from http://cdm16002.contentdm.oclc. org/cdm/ref/collection/p245801 coll10/id/405438

Gilroy, S. P., Lorah, E. R., Dodge, J., \& Fiorello, C. (2015). Establishing deictic repertoires in autism. Research in Autism Spectrum Disorders, 19, 82-92. doi:10.1016/j.rasd.2015.04.004.

Greer, B. D., Fisher, W. W., Romani, P. W., \& Saini, V. (2016). Behavioral momentum theory: a tutorial on response persistence. The Behavior Analyst, 39(2), 269-291. doi:10.1007/s40614-016-0050-0.

Hagge, M., \& Van Houten, R. (2016). Review of the application of the response deprivation model to organizational behavior management. Journal of Organizational Behavior Management, 36(1), 5-22. doi:10.1080/01608061.2016.1152208.

Hall, N. J., Smith, D. W., \& Wynne, C. D. L. (2015). Pavlovian conditioning enhances resistance to disruption of dogs performing an odor discrimination. Journal of the Experimental Analysis of Behavior, 103(3), 484 497. doi:10.1002/jeab. 151.

Hantula, D. A. (2016). Expanding the scope: beyond the familiar and beyond the page. The Behavior Analyst, 39(2), 189-196. doi:10.1007/s40614-016-0078-1.

Hausman, N. L., Borrero, J. C., Fisher, A., \& Kahng, S. (2017). Teaching young children to make accurate portion size estimations using a stimulus equivalence paradigm. Behavioral Interventions, 32(2), 121132. doi:10.1002/bin.1466.

Hayes, S. C. (2016). Acceptance and commitment therapy, relational frame theory, and the third wave of behavioral and cognitive therapies. Behavior Therapy, 47(6), 869-885. doi:10.1016/j.beth.2016.11.006.

Herrnstein, R. J. (1961). Relative and absolute strength of response as a function of frequency of reinforcement. Journal of the Experimental Analysis of Behavior, 4(3), 267-272. doi:10.1901/jeab.1961.4-267.

Herrnstein, R. J. (1970). On the law of effect. Journal of the Experimental Analysis of Behavior, 13(2), 243266. doi:10.1901/jeab.1970.13-243. 
Hineline, P. N. (1992). A self-interpretive behavior analysis. American Psychologist, 47(11), 1274-1286. doi:10.1037/0003-066X.47.11.1274.

Hursh, S. R. (1980). Economic concepts for the analysis of behavior. Journal of the Experimental Analysis of Behavior, 34(2), 219-238. doi:10.1901/jeab.1980.34-219.

Hursh, S. R., \& Roma, P. G. (2016). Behavioral economics and the analysis of consumption and choice. Managerial and Decision Economics, 37(4-5), 224-238. doi:10.1002/mde.2724.

Jacobs, K. W., Morford, Z. H., King, J. E., \& Hayes, L. J. (2017). Predicting the effects of interventions: a tutorial on the disequilibrium model. Behavior Analysis in Practice. doi:10.1007/s40617-017-0176-X.

Kaplan, B. A., Amlung, M., Reed, D. D., Jarmolowicz, D. P., McKerchar, T. L., \& Lemley, S. M. (2016). Automating scoring of delay discounting for the 21- and 27-item monetary choice questionnaires. The Behavior Analyst, 39(2), 293-304. doi:10.1007/s40614-016-0070-9.

Keenan, M. (2016). The scientific image in behavior analysis. The Behavior Analyst, 39(1), 7-8. doi:10.1007 /s40614-016-0059-4.

Kelly, L., \& Holloway, J. (2015). An investigation of the effectiveness of behavioral momentum on the acquisition and fluency outcomes of tacts in three children with autism Spectrum disorder. Research in Autism Spectrum Disorders, 9, 182-192. doi:10.1016/j.rasd.2014.10.007.

Konarski, E. A., Crowell, C. R., \& Duggan, L. M. (1985). The use of response deprivation to increase the academic performance of EMR students. Applied Research in Mental Retardation, 6(1), 15-31. doi:10.1016/S0270-3092(85)80019-9.

Konarski, E. A., Crowell, C. R., Johnson, M. R., \& Whitman, T. L. (1982). Response deprivation, reinforcement, and instrumental academic performance in an EMR classroom. Behavior Therapy, 13(1), 94-102. doi:10.1016/S0005-7894(82)80052-X.

Konarski, E. A., Johnson, M. R., Crowell, C. R., \& Whitman, T. L. (1980). Response deprivation and reinforcement in applied settings: a preliminary analysis. Journal of Applied Behavior Analysis, 13(4), 595-609. doi:10.1901/jaba.1980.13-595.

Konarski, E. A., Johnson, M. R., Crowell, C. R., \& Whitman, T. L. (1981). An alternative approach to reinforcement for applied researchers: response deprivation. Behavior Therapy, 12(5), 653-666. doi:10.1016/S0005-7894(81)80137-2.

Krakauer, J. W., Ghazanfar, A. A., Gomez-Marin, A., MacIver, M. A., \& Poeppel, D. (2017). Neuroscience needs behavior: correcting a reductionist bias. Neuron, 93(3), 480-490. doi:10.1016/j.neuron.2016.12.041.

Lambert, J. M., Bloom, S. E., Samaha, A. L., Dayton, E., \& Kunnavatana, S. S. (2016). Effects of noncontingent reinforcement on the persistence and resurgence of mild aggression. The Psychological Record, 66(2), 283-289. doi:10.1007/s40732-016-0170-7.

Ludwig, T. D., \& Houmanfar, R. (2009). Behavioral systems: understanding complex contingencies in organizations. Journal of Organizational Behavior Management, 29(2), 85-86. doi:10.1080 /01608060902874518.

Malott, M. E. (2016). Selection of business practices in the midst of evolving complexity. Journal of Organizational Behavior Management, 36(2-3), 103-122. doi:10.1080/01608061.2016.1200511.

McDowell, J. J. (1988). Matching theory in natural human environments. The Behavior Analyst, 11(2), 95-109.

McDowell, J. J., \& Caron, M. L. (2010). Bias and undermatching in delinquent boys' verbal behavior as a function of their level of deviance. Journal of the Experimental Analysis of Behavior, 93(3), 471-483. doi:10.1901/jeab.2010.93-471.

McDowell, C., \& Keenan, M. (2001). Developing fluency and endurance in a child diagnosed with attention deficit hyperactivity disorder. Journal of Applied Behavior Analysis, 34(3), 345-348. doi:10.1901 jaba.2001.34-345.

McGee, H. M., \& Diener, L. H. (2010). Behavioral systems analysis in health and human services. Behavior Modification, 34(5), 415-442. doi:10.1177/0145445510383527.

Murray, L. K., \& Kollins, S. H. (2000). Effects of methylphenidate on sensitivity to reinforcement in children diagnosed with attention deficit hyperactivity disorder: an application of the matching law. Journal of Applied Behavior Analysis, 33(4), 573-591. doi:10.1901/jaba.2000.33-573.

Nevin, J. A. (1996). The momentum of compliance. Journal of Applied Behavior Analysis, 29(4), 535-547. doi:10.1901/jaba.1996.29-535.

Nevin, J. A., Mandell, C., \& Atak, J. R. (1983). The analysis of behavioral momentum. Journal of the Experimental Analysis of Behavior, 39(1), 49-59. doi:10.1901/jeab.1983.39-49.

Nevin, J. A., \& Shahan, T. A. (2011). Behavioral momentum theory: equations and applications. Journal of Applied Behavior Analysis, 44(4), 877-895. doi:10.1901/jaba.2011.44-877.

Oliveira-Castro, J. M., Cavalcanti, P. R., \& Foxall, G. R. (2016). What consumers maximize: brand choice as a function of utilitarian and informational reinforcement. Managerial \& Decision Economics, 37(4-5), 360-371. doi:10.1002/mde.2722. 
Open Science Collaborative (2015). Estimating the reproducibility of psychological science. Science, 349(6251). doi:10.1126/science.aac4716.

Patterson, G. R. (1982). Coercive family process (Vol. 3): Eugene, OR: Castalia Publishing Company.

Patterson, G. R. (1986). Performance models for antisocial boys. American Psychologist, 41(4), 432-444. doi:10.1037/0003-066x.41.4.432.

Patterson, G. R. (1993). Orderly change in a stable world: the antisocial trait as a chimera. Journal of Consulting and Clinical Psychology, 61(6), 911-919. doi:10.1037/0022-006x.61.6.911.

Patterson, G. R. (2005). The next generation of PMTO models. Behavior Therapy, 28(2), 27-33.

Patterson, G. R. (2016). Coercion theory: the study of change. In T. J. Dishion \& J. J. Snyder (Eds.), The Oxford handbook of coercive relationship dynamics (pp. 7-22). New York, NY, US: Oxford University Press.

Patterson, G. R., DeBaryshe, B. D., \& Ramsey, E. (1989). A developmental perspective on antisocial behavior (Vol. 44): American Psychological Association.

Patterson, G., \& Reid, J. (1970). Reciprocity and coercion: two facets of social systems. In C. Neuringer \& J. L. Michael (Eds.), Behavior modification in Clinical psychology. New York: Appleton.

Patterson, G. R., \& Yoerger, K. (1997). A developmental model for late-onset delinquency. In D. W. Osgood (Ed.), Motivation and delinquency (pp. 119-177). Lincoln, NE, US: University of Nebraska Press.

Patterson, G. R., \& Yoerger, K. (2002). A developmental model for early- and late-onset delinquency. In J. B. Reid, G. R. Patterson, \& J. Snyder (Eds.), Antisocial behavior in children and adolescents: a developmental analysis and model for intervention (pp. 147-172). Washington, DC, US: American Psychological Association.

Peery, A., \& Fisher, W. W. (2001). Behavioral economic influences on treatments designed to decrease destructive behavior. Journal of Applied Behavior Analysis, 34(2), 211-215. doi:10.1901/jaba.2001.34211.

Pritchard, D., Hoerger, M., \& Mace, F. C. (2014). Treatment relapse and behavioral momentum theory. Journal of Applied Behavior Analysis, 47(4), 814-833. doi:10.1002/jaba.163.

Reed, D. D., Kaplan, B. A., Becirevic, A., Roma, P. G., \& Hursh, S. R. (2016). Toward quantifying the abuse liability of ultraviolet tanning: a behavioral economic approach to tanning addiction. Journal of the Experimental Analysis of Behavior, 106(1), 93-106. doi:10.1002/jeab.216.

Reimer, D., \& Houmanfar, R. A. (2017). Internalities and their applicability for organizational practices. Journal of Organizational Behavior Management, 37(1), 5-31. doi:10.1080/01608061.2016.1257969.

Rider, D. P. (1991). The speciation of behavior analysis. The Behavior Analyst, 14(2), 171-181.

Rivard, M., Forget, J., Kerr, K., \& Bégin, J. (2014). Matching law and sensitivity to therapist's attention in children with autism spectrum disorders. The Psychological Record, 64(1), 79-88. doi:10.1007/s40732014-0015-1.

Roane, H. S., Falcomata, T. S., \& Fisher, W. W. (2007). Applying the behavioral economics principle of unit price to DRO schedule thinning. Journal of Applied Behavior Analysis, 40(3), 529-534. doi:10.1901 /jaba.2007.40-529.

Roane, H. S., Kelley, M. E., Trosclair, N. M., \& Hauer, L. S. (2004). Behavioral momentum in sports: a partial replication with women's basketball. Journal of Applied Behavior Analysis, 37(3), 385-390. doi:10.1901 jjaba.2004.37-385.

Rutherford, A. (2006). The social control of behavioral control: behavior modification, individual rights, and research ethnics in America, 1917-1979. Journal of the History of the Behavioral Sciences, 42(3), 203220. doi:10.1002/jhbs.20169.

Scharf, I. (2016). The multifaceted effects of starvation on arthropod behaviour. Animal Behaviour, 119, $37-$ 48. doi:10.1016/j.anbehav.2016.06.019.

Shadish, W. R. (2014). Statistical analyses of single-case designs: the shape of things to come. Current Directions in Psychological Science, 23(2), 139-146. doi:10.1177/0963721414524773.

Sigurdsson, S. O., \& McGee, H. M. (2015). Organizational behavior management: systems analysis. In H. S. Roane, J. E. Ringdahl, \& T. S. Falcomata (Eds.), Clinical and organizational applications of applied behavior analysis (pp. 627-647). San Diego, CA, US: Elsevier Academic Press.

St. Peter, C. C., Vollmer, T. R., Bourret, J. C., Borrero, C. S. W., Sloman, K. N., \& Rapp, J. T. (2005). On the role of attention in naturally occurring matching relations. Journal of Applied Behavior Analysis, 38(4), 429-443. doi:10.1901/jaba.2005.172-04.

Tate, R. L., Perdices, M., Rosenkoetter, U., Shadish, W., Vohra, S., Barlow, D. H., et al. (2016). The singlecase reporting guideline in BEhavioural interventions (SCRIBE) 2016 statement. Journal of School Psychology, 56, 133-142. doi:10.1016/j.jsp.2016.04.001. 
Thirus, J., Starbrink, M., \& Jansson, B. (2016). Relational frame theory, mathematical, and logical skills: a multiple exemplar training intervention to enhance intellectual performance. International Journal of Psychology \& Psychological Therapy, 16(2), 141-155.

Timberlake, W., \& Allison, J. (1974). Response deprivation: an empirical approach to instrumental performance. Psychological Review, 81(2), 146-164. doi:10.1037/h0036101.

Timberlake, W., \& Farmer-Dougan, V. A. (1991). Reinforcement in applied settings: figuring out ahead of time what will work. Psychological Bulletin, 110(3), 379-391. doi:10.1037/0033-2909.110.3.379.

Tustin, R. D. (1994). Preference for reinforcers under varying schedule arrangements: a behavioral economic analysis. Journal of Applied Behavior Analysis, 27(4), 597-606. doi:10.1901/jaba.1994.27-597.

Zinn, T. E., Newland, M. C., \& Ritchie, K. E. (2015). The efficiency and efficacy of equivalence-based learning: a randomized controlled trial. Journal of Applied Behavior Analysis, 48(4), 865-882. doi:10.1002/jaba.258. 